\title{
PREVALENCE OF HELICOBACTER PYLORI INFECTION IN PATIENTS WITH ATROPHIC GASTRITIS AND ROLE OF DARK FIELD MICROSCOPY IN DIAGNOSIS
}

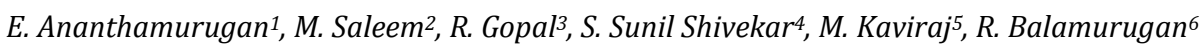

${ }^{1}$ Assistant Professor, Department of General Surgery, Sri Manakula Vinayagar Medical College \& Hospital, Madagadipet. ${ }^{2}$ Associate Professor, Department of Microbiology, Sri Manakula Vinayagar Medical College \& Hospital, Madagadipet. ${ }^{3}$ Professor \& HOD, Department of Microbiology, Sri Manakula Vinayagar Medical College \& Hospital, Madagadipet. ${ }^{4}$ Assistant Professor, Department of Microbiology, Sri Manakula Vinayagar Medical College \& Hospital, Madagadipet. ${ }^{5}$ Research Associate, Central Research Laboratory, Sri Manakula Vinayagar Medical College \& Hospital, Madagadipet. ${ }^{6}$ Research Scientist, Central Research Laboratory, Sri Manakula Vinayagar Medical College \& Hospital, Madagadipet.

\begin{abstract}
BACKGROUND: Helicobacter pylori is the most common human pathogen which causes chronic gastritis, leading to serious complications. The aim was to study the incidence of $\mathrm{H}$. pylori infection and the risk factors associated with chronic atrophic gastritis using simple diagnostic procedures.

MATERIALS AND METHODS: Biopsy samples were collected from 146 chronic atrophic gastritis patients. Rapid Urease Test (RUT) and dark field microscopy were used to diagnose the presence of H. pylori infection. The prevalence rate of H. pylori infection in relation to age, sex, smoking and alcohol consumption was studied.

RESULTS: 88 (60.27\%) cases were positive for RUT and also for the characteristic cork screw motility under dark field microscopy. Prevalence rate was high in younger age group and among female. We found no correlation of H. pylori infection with smoking and alcohol consumption.

CONCLUSION: It has been found that H. pylori is a major causative agent for atrophic gastritis and RUT is a simple cost efficient diagnostic test for H. pylori. The association of H. pylori infection with age, sex, smoking and alcohol consumption is variable and requires further studies to establish any relationship.
\end{abstract}

KEYWORDS: Gastritis, Helicobacter pylori, RUT, Dark field microscopy.

HOW TO CITE THIS ARTICLE: E. Ananthamurugan, M. Saleem, R. Gopal, S. Sunil Shivekar, M. Kaviraj, R. Balamurugan. "Prevalence of Helicobacter Pylori Infection in Patients with Atrophic Gastritis and Role of Dark Field Microscopy in Diagnosis." Journal of Evolution of Medical and Dental Sciences 2015; Vol. 4, Issue 93, November 19; Page: 15873-15875,

DOI: $10.14260 /$ jemds/2015/2304.

INTRODUCTION: Helicobacter pylori is a gram negative, microaerophile, colonizing the human gastric mucosa. It causes chronic inflammation of the mucosa which leads to various upper gastrointestinal (GI) disorders. $(1,2,3)$

Helicobacter pylori is found to be a major causative agent for gastritis. $(4,5)$ There are evidences that support the association of $\mathrm{H}$. pylori induced chronic atrophic gastritis with serious complications, like gastrointestinal bleeding, adenocarcinoma of stomach, etc. ${ }^{(6,7)}$ The bacterial colonization and the mechanism of inflammation include various factors. Adherence of the bacteria on the mucosal epithelium plays an important role in colonization, pathogenesis and inflammation. $\left.{ }^{8}\right)$

Adherence facilitates the absorption of nutrients and also helps the bacterium to evade immune attack.(9) The cytotoxins (e.g. vacuolating cytotoxin) produced by H. pylori directly causes cell damage. Protease and lipase produced by H. pylori and ammonia produced through urease activity also contribute to cell injury and inflammation. ${ }^{(10)}$

The prevalence of $\mathrm{H}$. pylori infection increases with respect to age and the risk factors associated with it varies among different parts of the world.(11)

Financial or Other, Competing Interest: None.

Submission 31-10-2015, Peer Review 02-11-2015,

Acceptance 10-11-2015, Published 18-11-2015.

Corresponding Author:

M. Saleem,

Associate Professor, Department of Microbiology,

Sri Manakula Vinayagar Medical College \& Hospital,

Madagadipet, Puducherry-605107, India.

E-mail: pondysaleem@gmail.com

DOI:10.14260/jemds/2015/2304.
The rate of $\mathrm{H}$. pylori infection is high in developing countries when compared to the developed countries.(12) Studies reveal that the socioeconomic status plays a vital role in the prevalence of $\mathrm{H}$. pylori. People with low socioeconomic status and those living in larger families, crowded populations, are more prone to $\mathrm{H}$. pylori infection. ${ }^{(13)} \mathrm{H}$. pylori infection spreads from person to person through vomitus, saliva, through the use of surface water resources like pond, river, etc. (14)

Lifestyle factors like cigarette smoking, tobacco chewing, alcohol consumption, food habits, etc., are also found to have an association with the prevalence of $H$. pylori infection. $(15,16,17)$ We aim to study the incidence of $\mathrm{H}$. pylori infection in patients with atrophic gastritis using rapid urease test (RUT) and dark field microscopic observations.

MATERIALS AND METHODS: A total of 146 patients with symptoms of Acid Peptic Disease (APD) comprising of 89 males and 57 females were diagnosed as suffering from chronic atrophic gastritis, by upper GI endoscopy. Written and informed consent was obtained from the patients. The study was conducted over a period of two months with the approval of institutional ethical committee. The age groups include $<30$, 31-40, 41-50, 51-60, 61-70 and $>70$. The habit of smoking and alcohol consumption of more than five years was found in 24 and 35 patients respectively.

Gastric antral biopsy samples taken from these patients were subjected to Rapid Urease Test (RUT) to detect the presence of urease producing Helicobacter pylori. The biopsy tissues were inoculated in $5 \mathrm{ml}$ of Christensen's urea broth ( $2 \%$ urea) and incubated for 24 hours at $37^{\circ} \mathrm{C}$. 
The urease positive samples were further observed under dark field microscopy for the presence of spiral-shaped, flagellated bacteria with its characteristic cork screw motility within 24 hours of sample collection from urease broth; $10 \%$ of urease negative samples were also examined by dark field microscopy for motile bacteria as described above as control for comparison.

RESULTS: Out of the 146 cases, $88(60.27 \%)$ were positive in the RUT. All the 88 samples which were found to be positive in urease test also exhibited the presence of spiral-shaped, flagellated, bacteria with characteristic cork screw motility by dark field microscopy. H. pylori positivity is found to be more $(72.72 \%)$ in the $<30$ age group (Table. 1$)$. There is no vast difference in the incidence rate of $\mathrm{H}$. pylori with respect to sex, smoking and alcohol consumption (Table No. 2 and 3). The prevalence of $\mathrm{H}$. pylori among smokers and non-smokers are $54.16 \%$ and $61.47 \%$ respectively. Among alcoholic and nonalcoholic, the prevalence rates are $54.28 \%$ and $62.16 \%$ respectively (Table No. 3).

DISCUSSION: Efficient diagnostic procedure is essential to study the prevalence of a particular pathogen. Two or more tests are said to be a gold standard for the diagnosis of $\mathrm{H}$. pylori.(18) Diagnosis of $\mathrm{H}$. pylori through RUT is an invasive technique. A single RUT is accepted as a confirmatory test for $\mathrm{H}$. pylori by taking the pretest probabilities of an infection into consideration.(19)

In our study, persistent clinical symptoms of more than six months, not responding to antacids was a measure of pretest probability for $\mathrm{H}$. pylori infection. Thereby RUT positivity alone can be considered as a confirmatory test. However, we examined for the presence of characteristic motile bacteria in the urease positive samples by dark field microscopy.

From the study we have found that $60.24 \%$ of patients were positive for $\mathrm{H}$. pylori infection. This shows H. pylori as an important causative agent of the atrophic gastritis..$^{(1,2,3)} \mathrm{H}$. pylori, upon colonization, releases chemotactic substances which causes accumulation of leucocytes, neutrophils and other inflammatory cells, thereby resulting in tissue injury and inflammation. $(8,20)$

The effect of age on the prevalence of H. pylori has been revealed through various studies. Most of the studies have shown that the prevalence of $\mathrm{H}$. pylori increases with increasing age. $(15,21,22)$ But there are studies that supports decreasing prevalence of $\mathrm{H}$. pylori infection with increasing age.(23) The results of our study shows that $\mathrm{H}$. pylori infection is more prevalent in the younger age group i.e., $<30$ years. $\mathrm{H}$. pylori infection acquired during early age, persists for a lifetime and if left untreated may result in $\mathrm{H}$. pylori induced chronic gastritis and carcinoma.

H. pylori infection in developing countries may be around $70 \%$, which is $40 \%$ in case of developed countries.(14) The vast difference between developed and developing countries may be due to the high probability of transmission in developing countries with a large population in the low socioeconomic group and poor hygienic practices, high population which facilitates person to person transmission, sharing pond and river as sources of drinking water, etc., which are the risk factors for high $\mathrm{H}$. pylori prevalence. $(12,13,24)$

We have studied the association of smoking and alcohol consumption with $\mathrm{H}$. pylori. Smoking suppresses the immune system which may facilitate the acquisition of $\mathrm{H}$. pylori. There are studies which support the fact that smokers are more susceptible to H. pylori infection. $(4,17)$ Some studies have stated no association of smoking with $\mathrm{H}$. pylori prevalence. ${ }^{(23,25)}$ The association of smoking with $\mathrm{H}$. pylori is contradictory. Our results show that $\mathrm{H}$. pylori is more prevalent in non-smokers than smokers. The results of our study agree with the work of Kikuchi, which supports a negative association of smoking with $\mathrm{H}$. pylori infection. The results supporting positive association of smoking with $\mathrm{H}$. pylori may have some other latent risk factors co-existing along with smoking.(14,26) Alcohol consumption was found to have no impact on the prevalence of H. pylori infection.(25)

The incidence of H. pylori in our study is less in alcoholics than non-alcoholics. This may be due to the antimicrobial effect of alcohol, which suppresses the survival of $\mathrm{H}$. pylori in the gastric mucosa. Moderate alcohol consumption may reduce the risk of $\mathrm{H}$. pylori infection. $(27,28)$

CONCLUSION: The prevalence of $\mathrm{H}$. pylori infection is independent of smoking and alcohol consumption. The prevalence rate is high among younger population and female. Dark field microscopic examination of urease positive samples is a simple inexpensive and useful supplementary test for diagnosis of $\mathrm{H}$. pylori infection.

ACKNOWLEDGEMENT: We acknowledge the services of technicians of Department of Microbiology of Sri Manakula Vinayagar Medical College and Hospital, for their valuable help.

\section{REFERENCES:}

1. Kenneth E.L. McColl. Helicobacter pylori Infection. N Engl J Med. 2010; 362:1597-1604.

2. Y. Vandenplas. Helicobacter pylori infection. Clin Microbial Infect. 1999 Jan; 5(1): 1-11.

3. Sebastian Suerbaum and Pierre Michetti. Helicobacter pylori Infection. N Engl J Med. 2002 Oct; 347:1175-1186.

4. Fontham ET, Ruiz B, Perez A, Hunter F, Correa P. Determinants of Helicobacter pylori infection and chronic gastritis. The American Journal of Gastroenterology.1995; 90(7):1094-1101.

5. Cornelius P. Dooley, Hartley Cohen, Patrick L. Fitzgibbons, Madeline Bauer, Maria D. Appleman, Guillermo I. Perez-Perez, and Martin J. Blaser. Prevalence of Helicobacter pylori Infection and Histologic Gastritis in Asymptomatic Persons. N Engl J Med. 1989 Dec; 321:1562-1566.

6. Wong-Ho Chow, Martin J. Blaser, William J. Blot, Marilie D. Gammon, Thomas L. Vaughan, Harvey A. Risen, Guillermo I. Perez-Perez, Janet B. Schoenberg, Janet L. Stanford, Heidi Rotterdam, A. Brian West, 3 and Joseph F. Fraumeni, J. An Inverse Relation between cagA+ Strains of Helicobacterpylori Infection and Risk of Esophageal and Gastric Cardia Adenocarcinoma. r. Cancer Research. 1998 Feb; 58: 588-590.

7. Martin J. Blaser, Guillermo I. Perez-Perez, Harry Kleanthous, Timothy L. Cover, Richard M. Peek, P. H. Chyou, Grant N. Stemmermann, and Abraham Nomura Infection with Helicobacter pylori Strains Possessing cagA Is Associated with an Increased Risk of Developing Adenocarcinoma of the Stomach. Cancer Research. 1995 May: 55; 2111-2115. 
8. Kaji T1, Ishihara S, Ashizawa N, Hamamoto N, Endo $\mathrm{H}$, Fukuda R, Adachi K, Watanabe M, Nakao M, Kinoshita YJ Lab Clin Med. Adherence of Helicobacter pylori to gastric epithelial cells and mucosal inflammation. 2002 Apr; 139(4): 244-50.

9. Ruggiero P. Helicobacter pylori and inflammation. Curr Pharm Des. 2010; 16(38): 4225-36.

10. Smoot DT. How does Helicobacter pylori cause mucosal damage? Direct mechanisms. Gastroenterology. 1997 Dec; 113(6): 31-4.

11. Taylor DN, Blaser MJ. The epidemiology of Helicobacter pylori infection. Epidemiol Rev. 1991; 13: 42-59.

12. David Y. Graham, Ervin Adam, Gurunath T. Reddy, Jai Prakash Agarwal, Rohit Agarwal, Doyle J. Evans Jr., Hoda M. Malaty, Dolores G. Evans. Seroepidemiology of Helicobacter pylori infection in India. Comparison of developing and developed countries. Dig Dis Sci. 1991 Aug: 36(8): 1084-1088.

13. H M Malaty, D Y Graham. Importance of childhood socioeconomic status on the current prevalence of Helicobacter pylori infection. Gut. 1994; 35: 742-745.

14. Linda Morris Brown. Helicobacter pylori: Epidemiology and Routes of Transmission. Epidemiol Rev. 2000, 22(2):283-297.

15. Ruihua Shi, Shunfu Xu, Hongjie Zhang, Yanbing Ding, Guiqian Sun, Xiayue Huang, Xiaoxing Chen, Xueliang Li1, Zhigang Yan and Guoxin Zhang. Prevalence and Risk Factors for Helicobacter pylori Infection in Chinese Populations Helicobacter. 2008 Apr; 13(2): 157-165.

16. Arvind Pandey, Satyendra Chandra Tripathi, Sutapa Mahata, Kanchan Vishnoi, Shirish Shukla, Sri Prakash Misra, Vatsala Misra, Suresh Hedau, Ravi Mehrotra, Manisha Dwivedi, Alok C. Bharti Carcinogenic Helicobacter pylori in gastric pre-cancer and cancer lesions: Association with tobacco-chewing. World J Gastroenterol. 2014 Jun; 20(22): 6860-6868.

17. Malcolm C. Bateson. Cigarette smoking and Helicobacter pylori infection. Postgrad Med J (1993) 69, 41 - 44.

18. Bermejo San Jose F, Boixeda de Miguel D, Gisbert JP, Martin de Argila de Prados C, Sanz Sacristan JM, Defarges Pons V, Moreno Almazan L, Garcia Plaza Plaza A. Efficacy of four widely used techniques of the diagnosis of Helicobacter pylori infection in gastric ulcer disease. Rev Clin Esp. 2000 Sep; 200(9): 475-9.

\begin{tabular}{|c|c|c|c|}
\hline Age & Total & $\begin{array}{c}\text { H. pylori } \\
\text { Positive }\end{array}$ & $\begin{array}{c}\text { Total } \\
\text { Positive \% }\end{array}$ \\
\hline$<30$ & 22 & 16 & $72.72 \%$ \\
\hline $31-40$ & 38 & 26 & $68.42 \%$ \\
\hline $41-50$ & 32 & 18 & $56.25 \%$ \\
\hline $51-60$ & 26 & 15 & $57.69 \%$ \\
\hline $61-70$ & 18 & 8 & $44.44 \%$ \\
\hline$>70$ & 10 & 5 & $50.00 \%$ \\
\hline
\end{tabular}

Table 1: Age wise Distribution of H. pylori Infected Cases

\begin{tabular}{|c|c|c|c|}
\hline Sex & Total & $\begin{array}{c}\text { H. pylori } \\
\text { Positive }\end{array}$ & $\begin{array}{c}\text { Total } \\
\text { Positive \% }\end{array}$ \\
\hline Male & 89 & 50 & $56.17 \%$ \\
\hline Female & 57 & 38 & $66.66 \%$ \\
\hline \multicolumn{4}{|r|}{ Table 2: Sex wise Distribution of H. pylori Infected Cases } \\
\hline
\end{tabular}

19. Takahiro Uotani and David Y. Graham Diagnosis of Helicobacter pylori using the rapid urease test. Ann Transl Med. 2015 Jan; 3(1): 9.

20. Norimasa Yoshida, D. Neil Granger, Doyle J. Evans Jr., Dolores G. Evans, David Y. Graham, Donald C. Anderson, Robert E. Wolf, and Peter R. Kvietys. Mechanisms involved in Helicobacter pylori-induced inflammation. Gastroenterology 1993:105:1431-1440.

21. Sender J. O. Veldhuyzen Van Zanten, P. Timothy Pollak, Linda M. Best, Gregory S. Bezanson and Thomas Marrie. Increasing Prevalence of Helicobacter pylori Infection with Age: Continuous Risk of Infection in Adults Rather than Cohort Effect. The Journal of Infectious Diseases. 1994 Feb; 169(2) 434-437.

22. Logan RP, Walker MM. ABC of the upper gastrointestinal tract: Epidemiology and diagnosis of Helicobacter pylori infection. BMJ. 2001 Oct; 323(7318):920-2.

23. Shaohua Chen, Lixiong Ying, Mei Kong, Yu Zhang, 3 and Youming Li. The prevalence of Helicobacter pylori infection decreases with older age in atrophic gastritis. Gastroenterology Research and Practice. 2013 Aug; 1-7.

24. Goodman KJ, Correa P, Tenganá Aux HJ, Ramírez H, DeLany JP, Guerrero Pepinosa O, López Quiñones M, Collazos Parra T. Helicobacter pylori infection in the Colombian Andes: A population-based study of transmission pathways. Am J Epidemiol. 1996; 144: 290 9.

25. Fraser AG1, Scragg R, Metcalf P, McCullough S, Yeates NJ. Prevalence of Helicobacter pylori infection in different ethnic groups in New Zealand children and adults. Aust N Z J Med. 1996 Oct; 26(5): 646-51.

26. Kikuchi S, Kurosawa M, Sakiyama T. Helicobacter pylori risk associated with sibship size and family history of gastric diseases in Japanese adults. Jpn J Cancer Res. 1999; 89: 1109-12.

27. Survey. Brenner H1, Berg G, Lappus N, Kliebsch U, Bode G, Boeing $\mathrm{H}$. Alcohol consumption and Helicobacter pylori infection: Results from the German National Health and Nutrition Epidemiology. 1999 May; 10(3): 214-8.

28. Kuepper-Nybelen J, Thefeld W, Rothenbacher D, Brenner H. Patterns of alcohol consumption and Helicobacter pylori infection: Results of a populationbased study from Germany among 6545 adults. Aliment Pharmacol Ther. 2005 Jan; 21(1): 57-64.

\begin{tabular}{|c|c|c|c|}
\hline \multicolumn{2}{|c|}{ Total } & Positive & Total Positive \% \\
\hline Smokers & 24 & 13 & $54.16 \%$ \\
\hline Non-smokers & 122 & 75 & $61.47 \%$ \\
\hline Alcoholic & 35 & 19 & $54.28 \%$ \\
\hline Non-alcoholic & 111 & 69 & $62.16 \%$ \\
\hline $\begin{array}{r}\text { Table 3: H. pylori Infection in Relation to } \\
\text { Smoking and Alcohol Consumption }\end{array}$ \\
\hline
\end{tabular}

